\title{
Versatility of Bipedicle Flap for Reconstruction of Large Scalp Defects
}

\author{
Yawar Sajjad, ${ }^{1}$ Muhammad Omar Afzal, ${ }^{2}$ Roomana Akhlaque, ${ }^{3}$ Samia Fatima, ${ }^{4}$ Beenish Rahat, ${ }^{5}$ Farrukh Aslam Khalid ${ }^{6}$ \\ 1,2,6Department of Burn and Reconstructive Surgery, Jinnah Burn and Reconstructive Surgery Center, Lahore-Pakistan, 34,5Department of Burn and Reconstructive Surgery, Lahore \\ General Hospital, Lahore-Pakistan
}

\section{ABSTRACT}

Background: Reconstruction of Scalp defects is a challenging problem. The unique hair bearing characteristics of scalp impose unique reconstructive challenges for coverage of scalp defects. Size, location and depth of the defect determine the complexity of the procedure. Patients with large scalp defects require reconstruction with broad based large scalp flaps. Objective: To determine the outcome of use of bipedicle scalp flap for coverage of large scalp defects. Study Design: Prospective \& Observational study. Settings: Department of Plastic Surgery, Lahore General Hospital and Jinnah Burn \& Reconstructive Surgery Centre Lahore-Pakistan. Duration: March 2010 to February 2019. Methodology: Eighteen patients of both genders with scalp defects secondary to trauma, tumor excision and burn injury were operated. Defect size more than $25 \mathrm{~cm}^{2}$ were included in the study. Those patients in which residual scalp tissue was traumatized or inadequate for scalp reconstruction were excluded from the study. The variables and outcome measures included size, location of defect, flap survival and donor site complications. Bipedicle flaps designed in different axis depending on location and size of the defect. Results: Out of 18 patients included in this study, 12(66.67\%) were male and $6(33.3 \%)$ female. Age ranged from 32 to $78 y e a r s$ (mean 48.66 ). Size of the defect ranged from $5.2 \times 10.4 \mathrm{~cm}$ to $18 \times 14 \mathrm{~cm}$. Postoperatively $14(77 \%)$ flaps survived completely while marginal flap necrosis and dehiscence seen in $2(11 \%)$ patients. Hospital stay on average was 11 days. Recovery was quick in all patients and wound healing was satisfactory. The mean follow up period was 8 months. Minor complications like hematoma seen in 1(5\%) patient. In $3(16 \%)$ patients there was partial graft loss at flap donor site that healed with conservative management. Conclusion: Bipedicle flap provides healthy, durable and hair bearing tissue with good cosmetic outcome. Large defects can be reconstructed with a simple technique.

Keywords: Bipedicle flap, Reconstruction, Scalp defects

Corresponding Author

Submitted for Publication: 01-03-2020

Dr. Yawar Sajjad, Associate Professor of Burn and Reconstructive Surgery, Jinnah Burn and Reconstructive Surgery Center, Lahore-Pakistan. Email: dryawar@gmail.com

Citation: Sajjad Y, Afzal MO, Akhlaque R, Fatima S, Rahat B, Khalid FA. Versatility of Bipedicle Flap for Reconstruction of Large Scalp Defects. APMC 2020;14(2):131-5.

\section{DOI: $10.29054 / A P M C / 2020.876$}

\section{INTRODUCTION}

The exposed location of the scalp makes it susceptible to wide variety of trauma and environmental insults. Majority of scalp defects result from oncologic resection, radio necrosis, burn injuries, infection and congenital malformations. ${ }^{1}$ Size, location and depth of defect determine the complexity of procedure and choice of reconstruction. ${ }^{2}$ In cases where pericranium is intact, split thickness graft is a simple and easy option. Scalp lacks elastic tissue; wound closure is not possible for defects greater than $3 \mathrm{~cm}$. Patients with large scalp defects with exposed calvarium or dura require coverage with vascularized flap. ${ }^{3}$

The various options are local, pedicle or free flaps. Scalp is unique in deriving its blood supply from bilateral paired arteries like superficial temporal, post auricular and occipital arteries. Due to the relative lack of flexibility of scalp, it is necessary to design larger local flaps for scalp defects. ${ }^{4}$ Scalp has rich blood supply and it can bear more tension than other tissues. For exposed cranium burring of outer table to promote granulation tissue. Exposed cranium with subsequent granulation tissue formation was covered successfully by skin graft. ${ }^{5-6}$

Among local flaps rotation advancement, transposition, orticochia and bipedicle flaps are the few options. Scalp wound demands early reconstruction if calvarial bone or dura is exposed. Microvascular free flap is an option for reconstruction for larger scalp defects. Long operative time required for micro vascular free flaps reconstruction in old age patients make it a secondary choice in such cases. There is always a search for a procedure, which is reliable, versatile and easy to perform in acute cases. The other milestones in scalp reconstruction are galeal scoring described in literature..$^{7-9}$

Local flaps have been described as reliable option for reconstruction of small to medium size scalp defects. ${ }^{10}$

In this case series we describe bipedicle flaps designed on different axis to cover large scalp defects.

\section{METHODOLOGY}

Study Design: Prospective \& Observational study.

Settings: Department of Plastic and Reconstructive Surgery at Lahore General Hospital Lahore and Jinnah Burn and Reconstructive surgery Centre, Lahore Pakistan.

Duration: March 2010 to February 2019.

Methods: Reconstruction in 18 patients with large scalp defects was done. Study variables including age, sex, etiology of wound, location of wound and size were recorded. Before planning bipedicle flap, remaining flap donor area of the scalp assessed for previous scar of trauma or surgery. Bipedicle flaps were designed in different axis depending on the location of the defect. 
The flap planned by marking two parallel incisions for coverage of defects. The flap designed 1.5 to two times larger than the defect size (fig 1-8). Before raising the flap infiltration with 20 to $30 \mathrm{ml}$ of $1 / 1000$ adrenaline done. While raising the flap wide undermining done in subgaleal plane. Galeal scoring of flap done to reduce tension in closure. Vascularity of flap derived from both sides paired vessels and 4:1 flap ratio to the size of the defect was achieved in all patients. The donor area of the flap was skin grafted with split thickness skin graft. Tie over foam dressing done over grafted skin.

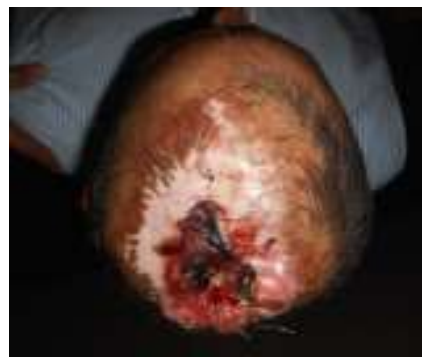

Figure 1: Marjolin ulcer frontoccipital region

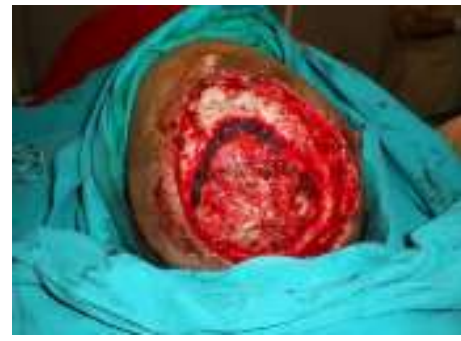

Figure 2: Defect after excision

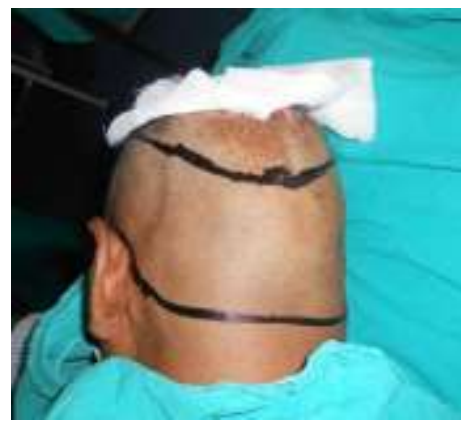

Figure 3: Flap marking

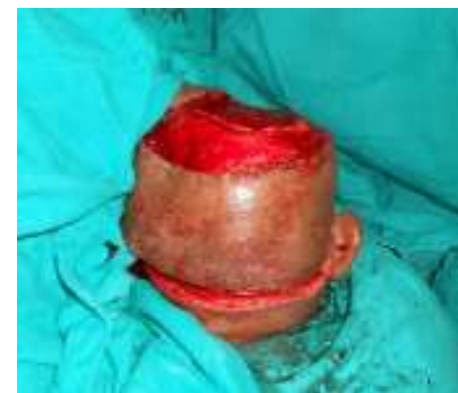

Figure 4: Flap raising

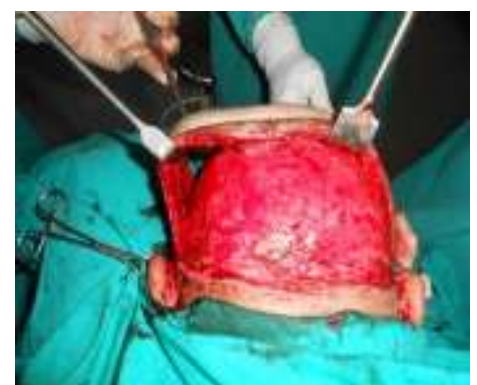

Figure 5: Flap insetting

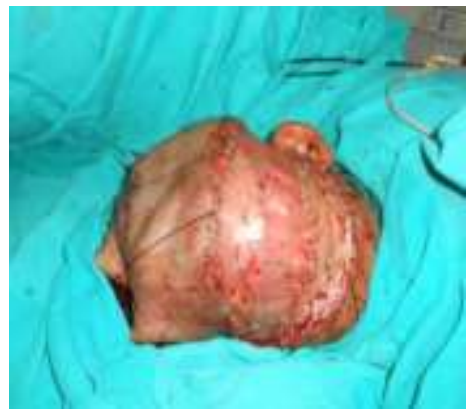

Figure 6: Donor site grafted

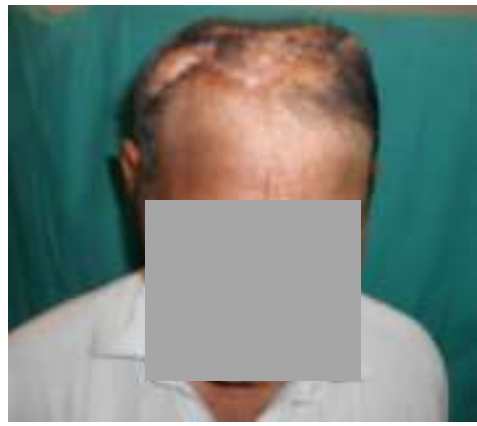

Figure 7: Follow up 4 months frontal view

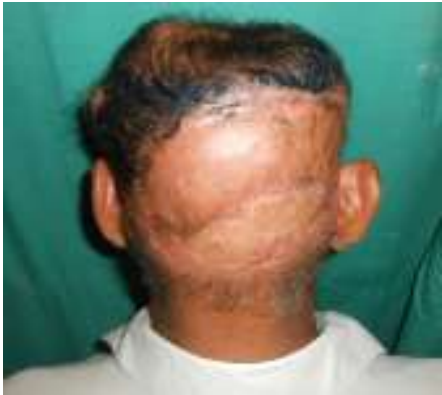

Figure 8: View from back

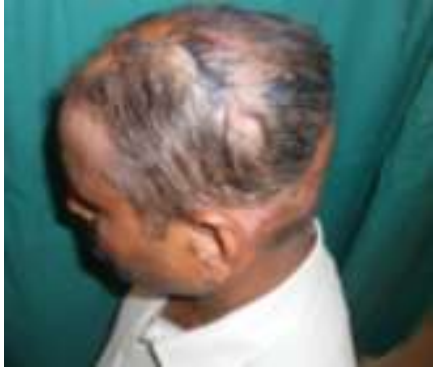

Figure 9: Side view 


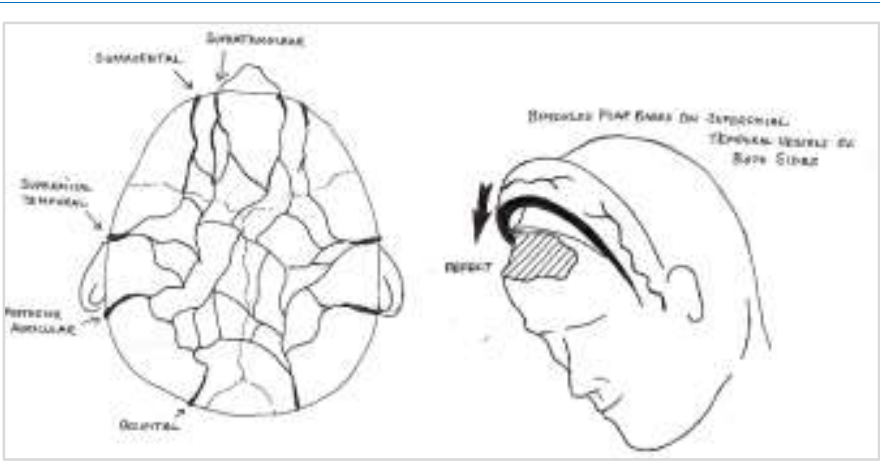

Figure 10: Blood supply and design of bipedicled flaps

\section{RESULTS}

Mean age of subjects were $48.667 \pm 12.141$ with minimum age of 32 and maximum age of $78.12(66.7 \%)$ were male, $6(33.3 \%)$ were female.10(55.6\%) patients were operated for tumor, $5(27.8 \%)$ patients for post traumatic defects and $3(16.7 \%)$ patients with post electrical burn injury. Location of defect 9 $(50.0 \%)$ had frontal, $8(44.4 \%)$ parietal and one $(5.6 \%)$ lateral parietal. 10(55.6\%) subjects had exposed bone and 8(44.4\%) had exposed dura. Tumor free margins were ensured after oncological resection in $10(55 \%)$ patients. In $2(11.1 \%)$ patient's fronto occipital flap planned for parietal defects. The flaps were based anteriorly on supraorbital vessels and posteriorly on occipital vessels. In $12(66.7 \%)$ patients temporo temporal flaps done for parietal and central frontal defects. In 4(22\%) patients temporo occipital flaps were designed for frontal and parietal defects. In 2(11\%) patients fronto occipital flaps were designed for frontal and parietal defects. All flaps healed and wound coverage was achieved. We were successful in achieving 4:1 flap ratio of the size of the defect. Stable repair and better cosmetic outcome observed after a follow up of 8 months and $6(27.8 \%)$ had complications. Among them $4(22 \%)$ had partial graft loss, $2(11 \%)$ had marginal flap necrosis and wound dehiscence. (Table1)

Table 1: Demographic and Clinical profile of subjects

\begin{tabular}{|l|l|l|l|}
\hline \multirow{2}{*}{ Age } & Variables $\mathbf{n = 1 8}$ & Frequency & Percent \\
\hline \multirow{3}{*}{ Gender } & $<50$ years & 11 & 61.1 \\
\cline { 2 - 4 } & 50 years & 7 & 38.9 \\
\hline \multirow{4}{*}{ Etiology } & Female & 6 & 33.3 \\
\cline { 2 - 4 } & Male & 12 & 66.7 \\
\hline \multirow{4}{*}{ Location } & Burn & 3 & 16.7 \\
\cline { 2 - 4 } & Trauma & 5 & 27.8 \\
\cline { 2 - 4 } & Tumor & 10 & 55.6 \\
\hline \multirow{3}{*}{ Pedicle } & Frontal & 9 & 50.0 \\
\cline { 2 - 4 } & Lateral Parietal & 1 & 5.6 \\
\cline { 2 - 4 } & Parietal & 8 & 44.4 \\
\hline \multirow{2}{*}{ Complications } & Exposed Bone & 10 & 55.6 \\
\cline { 2 - 4 } & Exposed Dura & 8 & 44.4 \\
\cline { 2 - 4 } & Fronto occipital & 2 & 11.1 \\
\cline { 2 - 4 } & Temporo occipital & 4 & 22.2 \\
\cline { 2 - 4 } & Temporo Temporal & 12 & 66.7 \\
\cline { 2 - 4 } & No & 6 & 27.8 \\
\hline \multirow{2}{*}{ No } & 13 & 72.2 \\
\hline
\end{tabular}

Mean=48.6667, SD=12.14132, Min=32.00, Max=78.00
Among the 2(11\%) patients in which dura repair was done by neurosurgeons, one $(5 \%)$ had minor CSF leakage which was managed by lumber drainage. Stable repair and better cosmetic outcome were observed after a follow up of 8 months. Wound dehiscence in $2(11 \%)$ patients treated with wound dressings. Partial graft loss and infection at the donor area were seen in $3(16 \%)$ patients. In these four patients, wound swab was taken for culture sensitivity and subsequent antibiotics with wound dressings resulted in satisfactory healing. Average operation time was two to two and half hours. Average wound healing time in all patients was 10 days. Hospital stay ranged from 8 to 14 days.

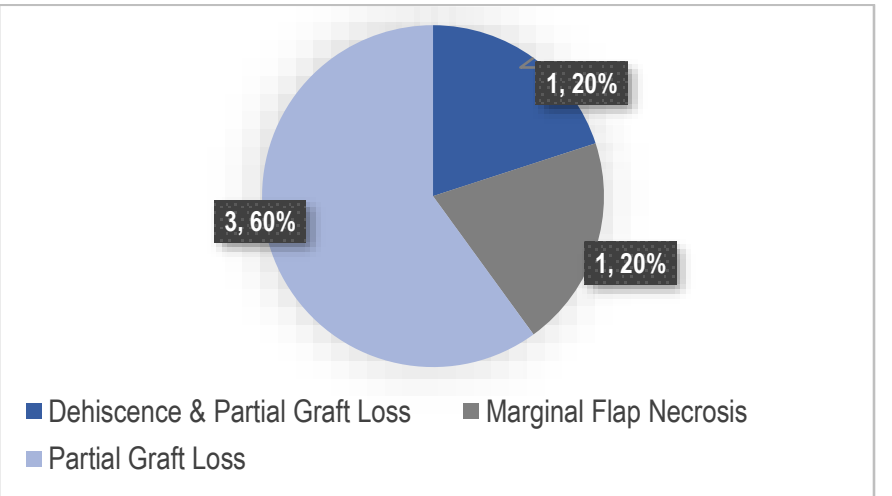

Graph no: 1 Complications among subjects $(n=5)$

\section{DISCUSSION}

Scalp reconstruction requires restoration and preservation of normal hair patterns. No other donor site in the body can provide the same hair bearing qualities of scalp tissue. ${ }^{11}$ Reconstruction with hair bearing skin can influence final aesthetic outcome. The goal of reconstruction is to obtain calvarial coverage to prevent calvarial desiccation, sequestration, and sepsis. The best replacement for scalp tissue is scalp that helps for achieving cosmetically appealing results in addition to merely achieving coverage. ${ }^{12}$

Most scalp defects can be reconstructed with local tissue rearrangements. Simple advancement of adjacent skin can be helpful for closure of defects up to $3 \mathrm{~cm}$.Local flaps for scalp reconstruction should be designed to incorporate at least one of these major scalp arteries to maintain an axial blood supply. Reconstruction of scalp defects requires proper assessment of defect. Larger defects can be reconstructed with scalp tissue by rotation, transposition and advancement flap or orticochea flap. Orticochea flaps were classically described for reconstruction of the occipital scalp. ${ }^{13}$

True Orticochea flaps are not ideally well suited for repair of parietal or vertex defects because the location does not allow for a large third flap for coverage of the donor-site defect and advancement from the contralateral parietal scalp up over the vertex is often inadequate for defect closure. ${ }^{14}$

The distal portion of unipedicle flaps lacks axial blood supply and does not receive blood from contralateral side, so more risk of necrosis at the distal most area of any local rotation flap. Bipedicle flaps designed with the largest possible base can be 
good option for large scalp defects. Bipedicle flaps have been successfully used for coverage of soft tissue defects of leg and abdomen. The main advantage of bipedicle flap is its reliability due to dual vascularity and greater length to width ratio as compared to local flaps. Bipedicle flap result in less visible scar in hair bearing scalp skin. Larger and complex scalp defects may require microvascular free tissue transfer for reconstruction. Pedicled myocutaneous flaps like latissimus dorsi and trapezius have been used to reconstruct inferior temporal or occipital scalp defects. The scalp defects in frontal or parietal region cannot be covered with pedicle flaps. In our patients, scalp defects were mainly located in the frontal and parietal region, which are not suitable sites for reach of pedicled flaps. Most commonly used microvascular free flaps for scalp reconstruction are radial forearm fasciocutaneous flap, scapular flap, anterolateral thigh flap, latissimus dorsi myocutaneous flap, rectus abdominis myocutaneous flap and omentum flap. ${ }^{15-18}$ The issues associated with microvascular free flaps are prolong surgical time, possibility of total flap loss in case of flap failure and morbidity of the donor area. Fasciocutaneous free flaps do not have enough skin and lack hair for scalp reconstrustion. ${ }^{19} \mathrm{~A}$ basic principle in plastic surgery is to reconstruct like with like and use the simplest technique available for reconstruction. In older age patients the large scalp defects are possible to reconstruct with rest of scalp tissue that help to save from the morbidity associated with free flaps. Hair bearing adjacent scalp is the ideal tissue for such reconstruction. ${ }^{20}$ Bipedicle flap has also been used successfully for coverage of wounds of abdomen and leg..$^{21}$ If executed adequately bipedicle flaps can ensure good results for large scalp defects. Adjacent scalp provides tissue of same thickness; texture and hair bearing. The advantages of bipedicle flaps include versatility and lack of morphological complications at donor site. There is no need of back cut to increase arc of flap in bipedicle flaps. ${ }^{22}$ Axial pattern of blood supply in bipedicle flaps is derived from both sides. We designed bipedicle flaps using the remaining available scalp tissue on two of the named vessels supplying scalp. Mobilization of flap done as per requirement of defect. Final outcome of reconstruction in bipedicle flap was much superior as compared to free flaps.

Scalp defects in older and debilitated patients can be managed with micro vascular free tissue transfer but old patients do not tolerate lengthy general anesthesia. ${ }^{23}$ Young patient's do not accept a significant area of alopecia that is seen with other techniques like healing by secondary intention, skin grafts, or free flaps. The advantages in local bipedicle flaps are healing time is rapid, wound is easy to manage and there is no distant donor site. The minimal morbidity associated with the bipedicle flap, the ease of its design, the speed of its performance and the simple postoperative follow-up make bipedicle flap an ideal option.

\section{CONCLUSION}

Bipedicle Scalp flap provides healthy, durable and hair bearing tissue with good cosmetic outcome. Large Scalp defects can be reconstructed with a simple technique.

\section{LIMITATIONS}

None

\section{SUGGESTIONS / RECOMMENDATIONS}

When donor site is available, a bipedicled flap should be utilized due to its more robust blood supply and greater percentage of flap survival as compared to unipedicled to flap.

\section{CONFLICT OF INTEREST / DISCLOSURE}

Authors have no conflict of interest to declare.

\section{ACKNOWLEDGEMENTS}

Neurosurgery department of Lahore General Hospital for their collaboration.

\section{REFERENCES}

1. Desai SC, Sand JP, Sharon JD, Branham G, Nussen baum B. Scalp reconstruction: an algorithmic approach and systematic review. JAMA Facial Plast Surg. 2015;17(1):56-66.

2. Leedy JE, Janis JE, Rohrich RJ. Reconstruction of acquired scalp defects: an algorithmic approach. Plast Reconstr Surg. 2005;116(4):54-72.

3. Karsidag S, Ozcan A, Ozkaya O.Use of wide bipedicledpericranialflap in anterior scalp reconstruction. J Craniofacial Surg. 2009;20(6):2248-51.

4. Shonka DC, Potash AE, Jameson MJ. Successful reconstruction ofscalp and skull defects: lessons learned from a large series. Laryngoscope.2011;121(11):2305-12.

5. Jin $Y$, Hua C, Hu X, Chen H, Ma G, Zou Y, Chen B, et al. Microsurgical Replantation of Total Avulsed Scalp: Extending the Limits. J Craniofac Surg. 2017;28(3):670-4.

6. Stojicic M, Jovanovic M, Rasulic L, Vitosevic F. Reconstruction of Large Acquired Scalp Defects: Ten-Year Experience. Turk Neurosurg. 2017;27(6):904-11.

7. Thakker JS, Fernandes R. Evaluation of reconstructive techniques for anterior and middle skull base defects following tumor ablation. J Oral Maxillofac Surg. 2014;72(1):198-204.

8. Jiafeng $\mathrm{L}$, Jiaming $\mathrm{S}$, XiaodanL. Auricular reconstruction using a novel three-flap technique improves the auriculocephalic angle. J Plast Reconstr Aesthet Surg. 2016;69(10):1430-5.

9. Sirimaharaj W. Scalp replantation: a case report of long ischemic time. J Med Assoc Thai. 2001;84(11):1629-34.

10. O'Connell DA1, Teng MS, Mendez E, Futran ND. Microvascular free tissue transfer in the reconstruction of scalp and lateral temporal bone defects. Craniomaxillofac Trauma Reconstr. 2011;4(4):179-88.

11. Uzun H, Bitik O, Ersoy US, Bilginer B, Aksu AE. Comparison of Musculocutaneous and Fasciocutaneous Free Flaps for the Reconstruction of the Extensive Composite Scalp and Cranium Defects. J Craniofac Surg. 2018;29(7):1947-51.

12. Steiner D, Hubertus A, Arkudas A, Taeger CD, Ludolph I, Boos AM, et al. Scalp reconstruction: A 10-year retrospective study. J Craniomaxillofac Surg. 2017;45(2):319-24.

13. Raposio E Scalp expansion: Surgical considerations and possible future directions. Indian J Plast Surg. 2018;51(1):84-8.

14. Arnold PG, Rangarathnam CS. Multiple-flap scalp reconstruction:Orticochea revisited. PlastReconstr Surg. 1982;69(4):605-13. 
15. Buncke HJ, Hoffman WY, Alpert BS, Gordon L, Stefani AE. Microvasculartransplant of two free scalp flaps between identical twins. Plast. Reconstr. Surg. 1982;70(5):605-9.

16. Sokoya M, Misch E, Vincent A, Wang W, Kadakia S, Ducic Y, Smith J. Free Tissue Reconstruction of the Scalp. Semin Plast Surg. 2019;33(1):67-71.

17. AlLababidi NH, Al Omran A, Hashem FK. The use of an omental flap for the reconstruction of a burn injury to the scalp: A case report. Int J Surg Case Rep. 2018;53:420-3.

18. Uzun H, Bitik O, Ersoy US, Bilginer B, Aksu AE. Comparison of Musculocutaneous and Fasciocutaneous Free Flaps for the Reconstruction of the Extensive Composite Scalp and Cranium Defects. J Craniofac Surg. 2018;29(7):1947-51.

19. Chicarilli ZN, Ariyan S, Cuono CB. Single-stage repair of complex scalp and cranial defects with the free radial forearm flap. Plast Reconstr Surg. 1986;77(4):577-85.

20. Kang SH, Kim YC, Sur YJ. Salibian H, Menick F J. Reverse turnover pedicled latissimus dorsi muscle flap for lower back reconstruction: Two case reports. Medicine (Baltimore). 2018;97(51):e13851.

21. Salibian AH, et al. Bipedicle gastrocnemius musculocutaneous flap for defects of the distal one-third of the leg. Plast Reconstr Surg.1982;70(1):17-23.

22. DeHaro F, Giraldo F. Bipedicled fronto-occipital flap for reconstruction of postoncologic defects of the lateral scalp. Plast ReconstrSurg. 2001;107(2):506-10.

23. Aslam MR, Rashid M,lllahi . Reconstruction of Scalp defects with free flaps. Pak J Plast Surg. 2013;2(1):26-30.

\section{AUTHORSHIP CONTRIBUTION}

Yawar Sajjad

Muhammad Omar Afzal

Roomana Akhlaque

Samia Fatima

Beenish Rahat

Farrukh Aslam Khalid
Manuscript Writing, Data Collection

Data Collection, General Review

Data Interpretation

Discussion

Formatting

General Review 